\title{
Hydrodynamics and Tidal Turbine Generator Stability Analysis in Several Wave Variations
}

\author{
Muhammad Ikhwan, ${ }^{1}$ Syamsul Rizal, ${ }^{1,2}$ Marwan Ramli $\mathbb{D}^{3}{ }^{3}$ Zainal A. Muchlisin, \\ and Said Munzir ${ }^{3}$ \\ ${ }^{1}$ Graduate School of Mathematics and Applied Sciences, Universitas Syiah Kuala, Banda Aceh 23111, Indonesia \\ ${ }^{2}$ Department of Marine Sciences, Faculty of Marine and Fisheries, Universitas Syiah Kuala, Banda Aceh 23111, Indonesia \\ ${ }^{3}$ Department of Mathematics, Faculty of Mathematics and Natural Science, Universitas Syiah Kuala, \\ Banda Aceh 23111, Indonesia \\ ${ }^{4}$ Department of Aquaculture, Faculty of Marine and Fisheries, Universitas Syiah Kuala, Banda Aceh 23111, Indonesia
}

Correspondence should be addressed to Marwan Ramli; marwan.math@unsyiah.ac.id

Received 1 November 2020; Accepted 7 June 2021; Published 16 June 2021

Academic Editor: Elena Kaikina

Copyright (C) 2021 Muhammad Ikhwan et al. This is an open access article distributed under the Creative Commons Attribution License, which permits unrestricted use, distribution, and reproduction in any medium, provided the original work is properly cited.

\begin{abstract}
The development of tidal turbines continues to be carried out by many researchers, including the incorporation of a control system for optimization purposes. This paper attempts to assess the stability of two mechanical systems in a tidal turbine: a propeller harvesting kinetic energy and a d-q diagram system on a permanent-magnet synchronous generator (PMSG). The method employed is the representation of a phase plane profile with a stable eigenvalue. The critical value of the turbine's rotations per minute provides some points of equilibrium. The effect of the angular velocity singular on the modified system was also investigated. There is no cutoff control for the generator rotational speed in the case of weak currents, according to the results. The combination of the three tidal turbine components results in a shift in the equilibrium point. Although PMSG has an infinite equilibrium point along the line $I_{d}=0$, the effect of the rotor angular velocity prevents all of these points from being in equilibrium. Finally, in this study, the rotor angular velocity caused by the speed and type of ocean currents are only the upper and lower limits. The stability of the various wave variations is within this range.
\end{abstract}

\section{Introduction}

This research was driven by a hydrodynamic laboratory's need to produce various types of waves in the wave container, including extreme waves. These waves will be used to test an oceanic object before it is operated, either in the middle of the ocean or near the land. Wind pressure, moving objects in water, and large-scale objects such as celestial bodies' gravity all contribute to the formation of waves. The ocean's kinetic energy is the most promising renewable energy as a substitution for the use of fossil energy. One of the energies that come from the sea is tidal energy, which has received many researchers' attention because of its regularity and certainty $[1,2]$. In both short and long term, tidal energy can be predicted with high accuracy. As a result, the power output of a specific tidal generator at a specific location can also be accurately estimated [3]. The advantages of tidal currents compared to wind resources are that seawater is denser than air and the ocean currents produce a more predictable resource than wind resource $[4,5]$.

The tidal turbine system uses a horizontal axis tidal current turbine system. This type of turbine has a better working efficiency than a turbine that rotates vertically at a performance coefficient of $\lambda=5$ [6]. A horizontal tidal turbine captures hydrodynamic energy and converts it to electricity using a generator. The generator commonly used is PMSG which has a weakness in the vulnerability to damage caused by the absence of a protection system between the turbine and generator [7]. Another study states that PMSG protection can be adopted from competing 
generators by adding a gearbox system [8]. In the development of PMSG, the control system at the propeller pitch angle is the best step to control the tidal turbine $[9,10]$. Pitch angle can assist to decrease a variety of errors, including turbine laying errors that do not match the tidal current direction [11].

Sangiuliano and Mastrantonis [12] investigated the benefits of tidal energy in Scotland. Offshore renewable energy has helped the transition from fossil energy to environmental-friendly energy. These drivers have prompted Scotland in developing and implementing the first ocean plan for consuming energy form tidal currents. Tidal turbine research has been carried out on the southwest coast of Yemen using a tidal current turbine (TCT) that uses ocean currents. Towers are used to harvest wind potential energy at maximum resource simultaneously. The combination structured between the wind turbine and tidal turbine is a cost-effective way that harvested energy [13]. Eme et al. [14] showed that the power product rate is immediately proportional to a hydrokinetic turbine's current speed. Therefore, the installation cost was drastically reduced by about $\$ 5,400$ per $\mathrm{kW}$. It is easy to assess the lack of mechanical and engine technology familiar to most turbine activists. Research examining technical efficiency has also been conducted by Wang and Wang [15]. The study compared tidal turbines, their advantages and disadvantages under various conditions, and several future modifications.

The installation of the existing tidal-stream turbines is carried out in energetic locations with flow rates of more than $2 \mathrm{~m} / \mathrm{s}$. Turbines operating in Mexico and the Philippines have current speeds below $1.5 \mathrm{~m} / \mathrm{s}$ [16]. Another study stated that a constant average speed of $0.81 \mathrm{~m} / \mathrm{s}$ could be used to install tidal turbine [17]. Tidal turbines were simulated along the Moroccan coast $(550 \mathrm{kM})$, and Nachtane et al. [18] recommend the three most strategic locations for tidal energy harvesting. The technical problems associated with the hydrodynamic design of the rotor blades due to marine turbine design are some of the techniques used for wind turbines. Arribas [4] describes a rotor design's projected hydrodynamics to extract maximum power from the tides. The theory of blade momentum is used for rotor modelling to overcome various aspects and limitations when applied to marine rotor designs. The use of tidal turbines can erode the seabed where the power plant is installed. Sun et al. [19] simulated the scouring effect of turbine-induced currents, followed by validation of the model through experimental data at an early stage. Simulation scale models were expanded to large-scale models for turbine scour estimation. However, the simulation misses the estimated about 15-20\% based on field-based data [20].

Tian et al. [21] reviewed and tested the prototype in a tower chamber. The field experimental data expressed the TCT is limited by a maximum speed of $0.25 \mathrm{~m} / \mathrm{s}$ and had an efficiency of about 0.33 . Fluid dynamics is based on the Reynolds Averaged Navier Stokes equation, and we carried out the computational simulation of the generator performances in both unstable and stable conditions. These models were mostly utilized in the distribution of polluted matter and flood calculations, but the model could be modified for waves and current simulation. The article studied the available one-to-three-dimensional computer application to analyze their validity to examine the TCT's energy that is free in ocean [22].

Li et al. [8] use a full-scale tidal current turbine to verify the design method with high reliability, and a TCT of $600 \mathrm{~kW}$ was used in that study. The turbine consists of a twopropeller rotor, a low rate gearbox, and a generator. Within the logical analysis and test results, satisfactory verification is achieved. Small-power turbines are frequently used on a laboratory scale with a generation method similar to tidal energy generation. Tides are often viewed from the gravity of celestial bodies against the Earth and wind [23-25]. The increase in wave amplitude is greatly influenced by the composition of the wave and its propagation as it moves from the middle of the sea to the land [26-28]. As a consequence, the observation of the turbine location takes into account the current strength, as indicated by the water ripples on the surface, as well as the internal current strength $[29,30]$.

\section{Materials and Methods}

There are many possible tidal current turbine arrangements. The planner can decide between straight impulse systems or gear-equipped systems. The two models of TCT are synchronous generator systems and indirect generator systems. The network's connection can be via a full-power converter, partial rated, or directly connected converter. The use of PMSG in a direct blade and generator is an engaging and frequently used vehicle by researchers. When used together with abundant power, the dynamo is separated from the network/grid, and a fully unsteady velocity process can be performed. Figure 1 gives the configuration regarded in the paper.

The system consists of a generator and maximum power converter, which consists of a back-to-back voltage source converter. This topology allows a two-way flow of current, and the others have completely regulated above the generator twist. An alternative is to practice a diode rectifier over PMSG, simplifying command, and reducing costs. The difficulties of using rectifier are often associated with power. Diode rectifiers have been reported to offer large harmonic distortion to the dynamo that affect efficiency and can produce harmonic torque.

The hydrodynamic torque developed by the turbine rotor in Figure 1 is [31]:

$$
\tau_{h}=\frac{0.5 \rho A v^{3} C_{p}(\beta, \lambda)}{\omega_{r}} .
$$

For modelling purposes, $C_{p}$ is power extraction efficiency. Tip speed ratio (TSR) $\lambda$ is determined based on current and rotor velocity. The first conditions are adjusted so that the rotor velocity is not zero. The estimated $\lambda$ and $\beta$ are later drafted for relevant values using $C_{p}$ listed in the table. The lookup table is for a generic $1 \mathrm{MW}$ TST rotor. After obtaining the values, the hydrodynamic torque is calculated. The model only turns the incident currents into a 
hydrodynamic twist and does not include dynamic flow effects, as seabed and tower influences.

The hydrodynamic twist caused by the rotor revolution is assigned for the dynamo via the impulse train. A directdrive system is used as a configuration indicating that the rotor is straightly related to a single bar that ends to a dynamo. For TCT modelling, a doubled mass system is governed in which both the bar and rotor are deemed whole combined mass, and the dynamo is the examined mass held together. The couple masses are attached within an adjustable bar with an inflexibility $K_{\mathrm{dt}}$ and an attenuation $D_{\mathrm{dt}}$. One point of the bar is pushed by a turbine rotor, providing torque $\tau_{h}$. The other point of the bar is saddled by the dynamo, which generates a twist $\tau_{g}$. The following system of equations describes the drive train:

$$
\begin{aligned}
\tau_{h} & =J_{r} \frac{d^{2} \theta_{r}}{\mathrm{dt}^{2}}+K_{\mathrm{dt}}\left(\theta_{r}-\theta_{g}\right)+D_{\mathrm{dt}}\left(\frac{d \theta_{r}}{\mathrm{dt}}-\frac{d \theta_{g}}{\mathrm{dt}}\right), \\
\tau_{g} & =J_{g} \frac{d^{2} \theta_{g}}{\mathrm{dt}^{2}}+K_{\mathrm{dt}}\left(\theta_{g}-\theta_{r}\right)+D_{\mathrm{dt}}\left(\frac{d \theta_{g}}{\mathrm{dt}}-\frac{d \theta_{r}}{\mathrm{dt}}\right), \\
\frac{d \theta_{r}}{\mathrm{dt}} & =\omega_{r}, \frac{d \theta_{g}}{\mathrm{dt}}=\omega_{g}, \omega_{g}=P_{p} \omega_{r},
\end{aligned}
$$

where $\theta_{r}$ and $\theta_{g}$ are the angular positions of the rotor and generator bar, $\omega_{r}$, and $\omega_{g}$ are the speed of rotor and generator bar, and $J_{r}$ and $J_{g}$ are the moment of inertia for the rotor and generator, respectively. $P_{p}$ is the number of pairing poles that made $\omega_{g}>\omega_{r}$. The electrical equalization used to the generator model is pictured in a rotating source framework. The $d$-axis is adapted simultaneously with the position of the rotor vector, and the $q$-axis affects the $d$-axis by a quarter circle degree. In this way, representing the electrical equation reduces the twist composing and flux magnetizing elements of the diesel. Therefore, it supports the improvement of a regulated plan that accommodates the self-governing regulator of twist.

Also, it is an area where surface vertical TCTs are hit with maximum average flow during flood and ebb cycles [32]. Turbulence is mostly insignificant when the TCT responds in regular harmonic waves. Martinez et al. [33] have shown that the usual flow thrust for the two turbine models and the same flow conditions is about twice as high as the thrust induced by turbulence. The turbulence effect is neglected for analysis purposes. With this approach, the turbine's power $\mathrm{P}$ in waves can be explained by the density-area-speed equation [17]:

$$
P=0.5 \rho A v^{3} C_{p}(\lambda, \beta),
$$

where $\rho$ express the fluid density of sea water, area $A=\pi r^{2}$ follows the circle cross section with the radius of the turbine $r, v$ is the current speed, $C_{p}$ is the turbine efficiency, $\beta$ represents the blade pitch angle, and $\lambda$ is the velocity ratio at the defined propeller tip shown as follows [34]:

$$
\lambda=\frac{\omega_{r} R_{s}}{v},
$$

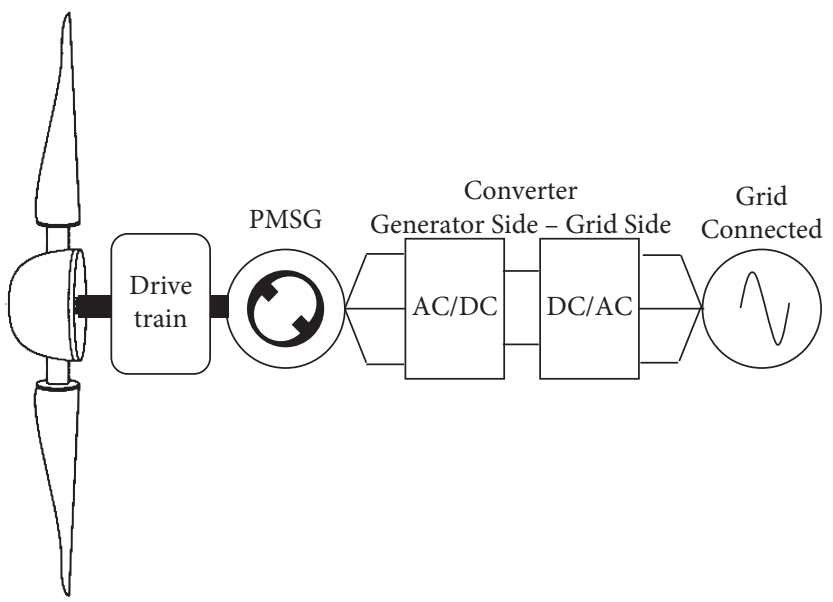

Figure 1: PMSG-based TCT [8].

where $\omega_{r}$ is the rotor angular velocity.

The TCT system uses a motor rotation system, gearbox, and generator. This system is structured with a control system structure with the assumption that combining three elements in one unit, the equation can be formulated as in [35]. The gearbox has a significant impact on determining the angular velocity value of each shaft. Equation (2) applies linearly in the absence of the gearbox [36]. However, if a gearbox is added, equation (2) is modified by viscous friction to the following equation:

$$
J_{\text {eq }} \dot{\omega}_{r}=\tau_{g}-\tau_{\mathrm{hg}}-V_{f} \omega_{r},
$$

where $J_{\mathrm{eq}}$ is the inertia equivalency of $J_{r}$ and $J_{g}$, where $J_{\mathrm{eq}}=J_{g}+J_{r} / n_{g}^{2}$ and $n_{g}$ is the gear ratio. From this structure, $V_{f}$ is the friction of the viscous coefficient. Torque $\tau_{\mathrm{hg}}$ is obtained from $\tau_{h} / n_{g}$, and $\tau_{g}$ is derived from the $\mathrm{d}$-q diagram of the generator as follows [37]:

$$
\begin{aligned}
L_{d} \dot{I}_{d} & =u_{d}-R_{s} I_{d}+L_{q} \omega_{g} I_{q}, \\
L_{q} \dot{I}_{q} & =u_{q}-L_{d} \omega_{g} I_{d}-R_{s} I_{q}-\phi_{m} \omega_{g}, \\
\tau_{g} & =\frac{3}{2} P_{p}\left[\phi_{m}+\left(L_{d}-L_{q}\right) I_{d}\right] I_{q},
\end{aligned}
$$

where $L_{d}$ and $L_{q}$ are the direct inductance and its quadrature stator and $u_{d}$ and $u_{q}$ are the related voltage with the inductances. $I_{d}$ and $I_{q}$ represent the stator currents, and $\varphi_{m}$ is the permanent magnet flux. The hydrodynamic and generator parameters can be seen in Table 1 .

\section{Results and Discussion}

3.1. Model Linearization and Parameter Simplification. By paying attention to the relationship between $\omega_{r}$ and $\omega_{g}$ in equation (2), equations (6) and (7) are modified to $\omega_{r}$. The aim is to make it easier to get the $\tau_{g}$ value. The generator rotation is adjusted optimally by reducing its angular velocity. The implication is that a hydrodynamic torque 
TABLE 1: Hydrodynamic and generator parameters [35].

\begin{tabular}{lccc}
\hline Parameter symbol & Value & Parameter symbol & Value \\
\hline $\mathrm{P}$ & $1025 \mathrm{psu}$ & $\varphi_{m}$ & $6.8973 \mathrm{Vs}$ \\
$\mathrm{A}$ & $355 \mathrm{~m}^{2}$ & $V_{f}$ & 0.3 \\
$v$ & $2.4 \mathrm{~m} / \mathrm{s}$ & $J_{\mathrm{eq}}$ & $100 \mathrm{~kg} \mathrm{~m}^{2}$ \\
$C_{p}$ & 0.39 & $R_{s}$ & $4.61 \mathrm{~m} \Omega$ \\
$P_{p}$ & 60 pairs & $L$ & $886.48 \mu \mathrm{H}$ \\
\hline
\end{tabular}

regulator is required based on the speed of the propeller. Equation (5) can be obtained optimally by solving the following series of differential equations:

$$
\begin{aligned}
\frac{d \omega_{r}}{\mathrm{dt}} & =\frac{1}{J_{\mathrm{eq}}}\left(\tau_{g}-\tau_{h g}-V_{f} \omega_{r}\right), \\
\frac{\mathrm{dI}_{d}}{\mathrm{dt}} & =\frac{u_{d}}{L}-\frac{R_{s}}{L} I_{d}+P_{p} \omega_{r} I_{q}, \\
\frac{\mathrm{dI}_{q}}{\mathrm{dt}} & =\frac{u_{q}}{L}-P_{p} \omega_{r} I_{d}-\frac{R_{s}}{L} I_{q}-\frac{P_{p}}{L} \phi_{m} \omega_{r},
\end{aligned}
$$

where there is a simplification of the parameter $L_{\mathrm{d}}=L_{\mathrm{q}}=L$.

Furthermore, model (9) is linearized with the Jacobian matrix $J$ as follows:

$$
J=\left[\begin{array}{ccc}
\frac{\rho A v^{3} C_{p}}{2 J_{\mathrm{eq}} n_{g} \omega_{r}^{2}}-\frac{V_{f}}{J_{\mathrm{eq}}} & 0 & -\frac{3 P_{p} \phi_{m}}{2 J_{\mathrm{eq}}} \\
P_{p} \mathrm{I}_{q} & -\frac{R_{s}}{L} & P_{p} \omega_{r} \\
-P_{p} \mathrm{I}_{d}-\frac{P_{p}}{L} \phi_{m} & -P_{p} \omega_{r} & -P_{p}
\end{array}\right] .
$$

Matrix $J$ is used as the linear form of equation (9) and is useful for obtaining eigenvalues.

3.2. Equilibrium and Eigenvalues. The equilibrium point is obtained from the condition of the first derivative of each state variable with a value of zero. It means that the condition is on a straight gradient and is considered stable.

$$
\begin{array}{r}
\frac{1}{J_{e q}}\left(\tau_{g}-\tau_{h g}-V_{f} \omega_{r}\right)=0, \\
\frac{u_{d}}{L}-\frac{R_{s}}{L} I_{d}+P_{p} \omega_{r} I_{q}=0, \\
\frac{u_{q}}{L}-P_{p} \omega_{r} I_{d}-\frac{R_{s}}{L} I_{q}-P_{p}=0 .
\end{array}
$$

The equilibrium point is proposed at the limit conditions $\omega_{r}$ of $13 \mathrm{rpm}$ or $81.68 \mathrm{rad} / \mathrm{s}$. Equation (8) shows that the rotor flux is constant and the d-axis current component is always equal to zero. As a result, the electric torque is proportional to the current along the $q$-axis. Solution $I_{d}$ and $I_{q}$ on equation (11) is at the equilibrium point $\left(I_{d}, I_{q}\right)=(0,0)$. Some points, the proposed theory and equilibrium points, have stability that is checked by the eigenvalue. The eigenvalues formed can be seen in Table 2 .

The eigenvalues correspond to $\omega_{r}, I_{d}$, and $I_{q}$. The three eigenvalues at the negative pole mean that this model is stable around the equilibrium point. When the state variable is reduced to $I_{d}$ and $I_{q}$, all points near $I_{d}=0$ have negative eigenvalues. The system in equation (11) is rarely used in research involving the combination of rotors, gearboxes, and generators. This is because obtaining a stable point is difficult. Negative eigenvalues are asymptotically stable for all pairs of $I_{q}$ with $I_{d}=0$. However, because of the system's influence of $\omega_{r}$, only a very large position $I_{d}$ can produce a stable equilibrium point. This condition is outside the range of $I_{d}$ movements, so this equilibrium point has never been reached in practice.

The rotation speed of the generator determines the amount of energy produced in the generator system. Several studies have shown that the success of the TCT in harvesting tidal energy has been widely proven in theory, simulation, and in the field. The energy under review is only limited to the propeller until it reaches the generator side converter. Meanwhile, the grid side converter has other problems that are not reviewed in this article. Based on the review results, the turbines are mostly placed in narrow straits or canals, and in some cases, they are placed in shallow waters. The desired power efficiency is in the range of $0.33-0.39$, with a speed limit of less than $2 \mathrm{~m} / \mathrm{s}$.

The phase plane is away from the line $I_{d}=0$ and runs well in its surroundings. The relationship between $I_{d}$ and $\omega_{r}$ cannot be seen because the phase plane is not formed, while $I_{q}$ and $\omega_{r}$ result in a separate pattern by limit $\omega_{r}=[-81.68$, 81.68]. The value of $\omega_{r}$ depends on $I_{q}$ due to the simplification of the parameter $\mathrm{L}$ which causes the $I_{d}$ value to stick to equation (8) (see Figure 2).

Colour change in Figure 2 describes the $\omega_{r}$ range from the lower to the upper limit. The PMSG used is limited to $\omega_{r}=[-81.68,81.68]$, but the figure shows possible out-ofrange values. The green area has a low angular velocity and is located on the line $I_{q}=0$. Changes in stator current continue to grow away from the point $I_{d}=0$, indicating that this is the optimal area for producing constant energy. Outside of the green zone, we refer to it as the cutoff zone or extreme.

The cases of high and extreme waves with extraordinary strength cannot be explained on the stability curve. However, the power more significant than the $13 \mathrm{rpm}$ rotation of the turbine can be described if the system cutoff is not applied in real conditions. Extreme waves are waves with great strength and are a combination of waves that have the same phase and reinforce each other [27]. If the system has no cutoff, this wave can damage the system, when $\omega_{r}<-81.68$ and $\omega_{r}>81.68$. The twist on the curve becomes very large from the steady-state. Figure 3 shows the curve movement is no longer the same if $\omega_{r}$ is very large. The electric current strength of the generator in full negative and positive conditions is the opposite of each other.

The stator current changes that occur in the cutoff zone are more dynamic. For extracting energy, only a limited range is provided. Moving slightly to the $I_{d}>0$ area, the change immediately enlarges and tends to flatten out in very 
TABLE 2: The eigenvalues at some equilibrium points.

\begin{tabular}{|c|c|c|c|}
\hline Test point $\left(\omega_{r}, I_{d}, I_{q}\right)$ & $\begin{array}{c}\text { Eigen real } \\
\text { number }\end{array}$ & $\begin{array}{c}\text { Eigen imaginary } \\
\text { number }\end{array}$ & Stability note \\
\hline$(-81.68,0,0)$ & $\begin{array}{c}0.0162 \\
-5.2003 \times 10^{-3} \\
-5.2003 \times 10^{-3} \\
\end{array}$ & $\begin{array}{c}0 \\
-4.9009 \times 10^{3} \\
4.9009 \times 10^{3} \\
\end{array}$ & $\begin{array}{l}\text { Not stable } \\
\text { Not equilibrium } \\
\text { Extreme point }\end{array}$ \\
\hline$(0,0,0)$ & - & - & $\begin{array}{l}\text { Not defined by division } \\
\text { by zero }\end{array}$ \\
\hline$(81.68,0,0)$ & $\begin{array}{c}0.0162 \\
-5.2003 \times 10^{-3} \\
-5.2003 \times 10^{-3} \\
\end{array}$ & $\begin{array}{c}0 \\
-4.9009 \times 10^{3} \\
4.9009 \times 10^{3} \\
\end{array}$ & $\begin{array}{c}\text { Not stable } \\
\text { Not equilibrium } \\
\text { Extreme point } \\
\end{array}$ \\
\hline $\begin{array}{l}\left(1.9777 \times 10^{-10}-8.6672 \times 10^{-5} i, 2.3766 \times 10^{5}-1.9116 \times 10^{-13} i,\right. \\
\left.5.4230 \times 10^{-1}+2.3766 \times 10^{5} i\right)\end{array}$ & $\begin{array}{c}-0.0052 \\
-0.0104 \\
-1.7021 \times 10^{10} \\
\end{array}$ & $\begin{array}{c}0 \\
0 \\
7.7680 \times 10^{4} \\
\end{array}$ & $\begin{array}{l}\text { Asymptotically stable } \\
\text { Equilibrium point }\end{array}$ \\
\hline $\begin{array}{l}\left(1.9777 \times 10^{--10}+8.6672 \times 10^{-5} i, 2.3766 \times 10^{5}+1.9116 \times 10^{-13} i,\right. \\
\left.5.4230 \times 10^{-1}-2.3766 \times 10^{5} i\right)\end{array}$ & $\begin{array}{c}-0.0052 \\
-0.0104 \\
-1.7021 \times 10^{10} \\
\end{array}$ & $\begin{array}{c}0 \\
0 \\
-7.7680 \times 10^{4} \\
\end{array}$ & $\begin{array}{l}\text { Asymptotically stable } \\
\text { Equilibrium point }\end{array}$ \\
\hline $\begin{array}{l}\left(-1.9777 \times 10^{-10}+2.0645 \times 10^{2} i,-0.0078\right. \\
\left.-1.91161 \times 10^{-13}+9.4334 \times 10^{-8} i\right)\end{array}$ & $\begin{array}{c}1.2387 \times 10^{4} \\
-0.0060 \\
-1.2387 \times 10^{4} \\
\end{array}$ & $\begin{array}{c}1.8712 \times 10^{-8} \\
0 \\
-1.8712 \times 10^{-8} \\
\end{array}$ & $\begin{array}{l}\text { Not stable } \\
\text { Equilibrium point }\end{array}$ \\
\hline $\begin{array}{l}\left(-1.9777 \times 10^{-10}-2.0645 \times 10^{2} i,-0.0078,\right. \\
\left.-1.91161 \times 10^{-13}-9.4334 \times 10^{-8} i\right)\end{array}$ & $\begin{array}{c}1.2387 \times 10^{4} \\
-0.0060 \\
-1.2387 \times 10^{4} \\
\end{array}$ & $\begin{array}{c}-1.8712 \times 10^{-8} \\
0 \\
1.8712 \times 10^{-8}\end{array}$ & $\begin{array}{l}\text { Not stable } \\
\text { Equilibrium point }\end{array}$ \\
\hline
\end{tabular}

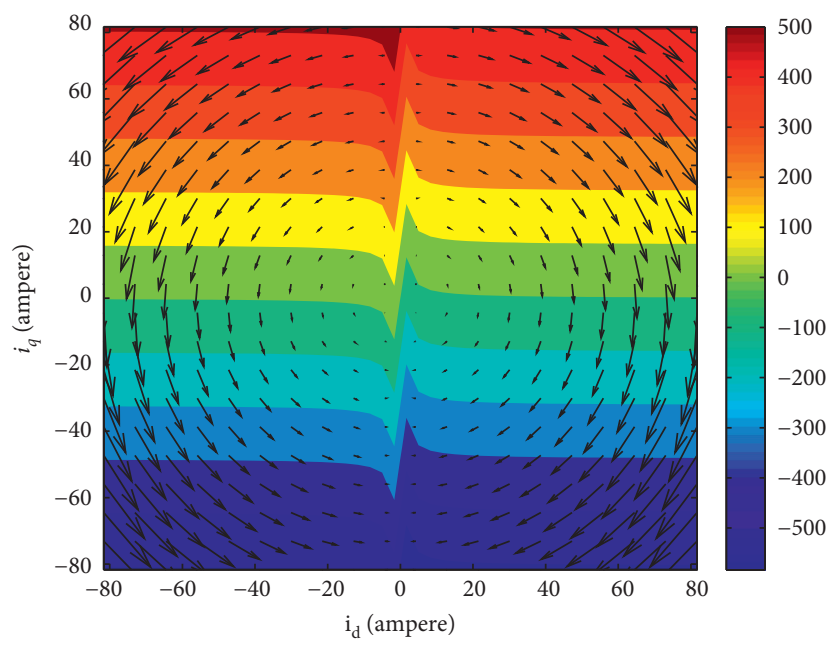

Figure 2: The stability of the generator based on the stator current d-q; the black quiver indicates the direction of change in $I_{d}-I_{q}$, and the color shade indicates $\omega_{r}$.

large $\omega_{r}$. That is, the effect of a change in $I_{d}$ is greater than the effect of a change in $I_{q}$, resulting in contradictory events when compared to equation (8), which is only influenced by $I_{q}$ [36]. According to these findings (Figure 2 and Table 2), the $I_{d}$ boundary should be updated, so that the equilibrium region is near the line $I_{d}=0$ or in the vicinity of the singular value $\omega_{r}$.

The simulation in the green area is shown using the parameters in Table 1. The simulation is run without the use of any input interference, such as rotor and generator speed control. The blade-side torque change appears normal in
Figures 3(a) and 3(b), but the torque generator remains small. Since friction has no effect on the torque on the blade, the value remains very high. The value of viscosity friction occurs when $\tau_{h}$ is converted to $\tau_{g}$, and even though the gearbox has increased the value of $\tau_{g}$, the value of $\tau_{g}$ will remain small. As a result, the current can expand to greater than $2.4 \mathrm{~m} / \mathrm{s}$, which is known as the minimum current velocity when hitting the blade in other studies. Figures 3(c) and $3(\mathrm{~d})$ show that $I_{d}$ and $I_{q}$ remain stable. As previously explained in Figure 2, $I_{q}$ can be increased around $I_{q}=0$. In the same case, $I_{q}$ is increased and controlled by the blade 


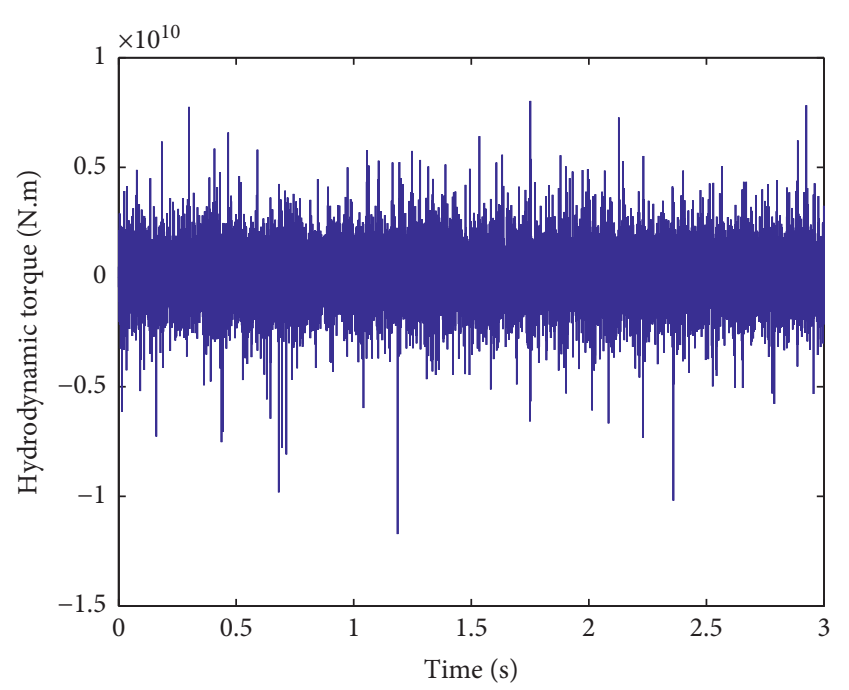

(a)

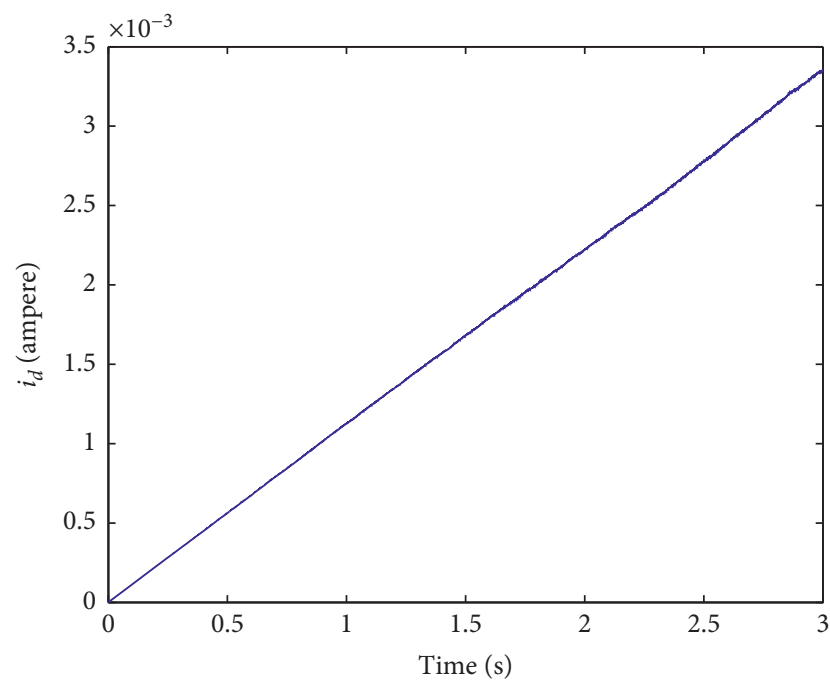

(c)

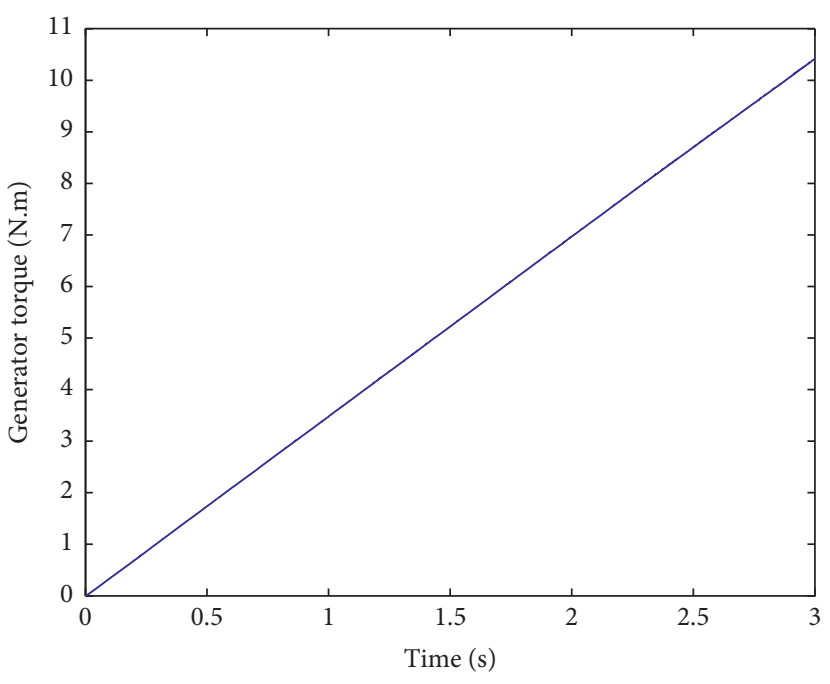

(b)

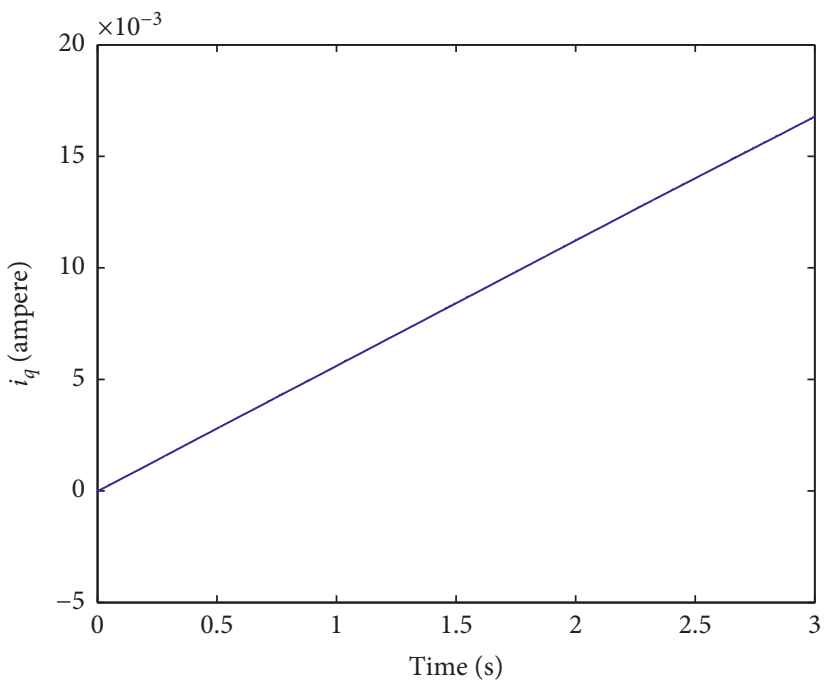

(d)

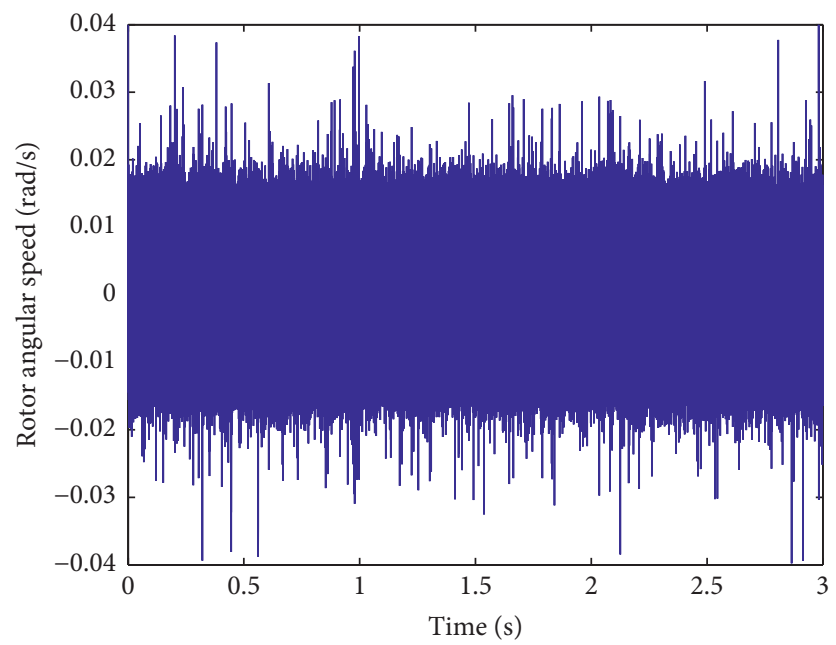

(e)

FIGURE 3: Hydrodynamic simulation at low-velocity current $\left(2.4 \mathrm{~m} / \mathrm{s}\right.$ ): (a) hydrodynamic torque $\tau_{h}$, (b) generator torque $\tau_{g}$, (c) d-axis stator current $i_{d}$, (d) q-axis stator current $i_{q}$, and (e) rotor angular speed $\omega_{r}$. 
pitch angle, so that $I_{q}$ approaches -2 , the rotor angular speed approaches $13 \mathrm{rpm}$, and the power reaches $1 \mathrm{MW}$ [35].

\section{Conclusions}

This study discovered a positive relationship between angular velocity and q-axis stator current in low-speed PMSG generators, whereas d-axis stator current had no effect on the other two state variables. The d-axis stator current provided a stable condition around its zero value. This condition changes when the rotor's angular speed reaches the limit of -13 to $13 \mathrm{rpm}$, a condition in which the PMSG tries to remain stationary while rapidly moving away from the point of equilibrium. Although the eigenvalues at each pole are negative, the real value formed is very small and close to 0 . When the rotor's angular velocity is greater than -13 to $13 \mathrm{rpm}$, the d-axis tolerance of the stator current becomes smaller. Current changes are becoming larger and more volatile. The result may be detrimental to the turbine structure. The gearbox system also performs well; at lowcurrent speed simulations, the torque on both sides of the gearbox can vary significantly, necessitating a minimum value of ocean current speed.

\section{Data Availability}

No datasets were generated or analyzed during the current study.

\section{Conflicts of Interest}

The authors declare that there are no conflicts of interest regarding the publication of this paper.

\section{Acknowledgments}

The authors thank Universitas Syiah Kuala for facility support at the Ocean Modelling Laboratory during the research. They would like to express their gratitude to the Ministry of Education and Culture of Indonesia for financial assistance in term "Penelitian Program Riset Unggulan Universitas Syiah Kuala Percepatan Doktor," under contract number 323/UN11.2.1/PT.01.03/PNBP/2020, and "Penelitian Dasar," under contract number 80/UN11.2.1/ PT.01.03/DRPM/2020.

\section{References}

[1] J. Zheng, P. Dai, and J. Zhang, "Tidal stream energy in China," Procedia Engineering, vol. 116, no. 1, pp. 880-887, 2015.

[2] C. R. Vogel, R. H. J. Willden, and G. T. Houlsby, "Tidal stream turbine power capping in a head-driven tidal channel," Renewable Energy, vol. 136, pp. 491-499, 2019.

[3] C. R. Vogel, R. H. J. Willden, and G. T. Houlsby, "Blade element momentum theory for a tidal turbine," Ocean Engineering, vol. 169, pp. 215-226, 2018.

[4] F. P. Arribas, "Hydrodynamic design of rotor blades of marine current turbines," IOP Conference Series: Earth and Environmental Science, vol. 354, no. 1, Article ID 012004, 2019.

[5] K. Ghefiri, A. Garrido, E. Rusu, S. Bouallègue, J. Haggège, and I. Garrido, "Fuzzy supervision based-pitch angle control of a tidal stream generator for a disturbed tidal input," Energies, vol. 11, no. 11, p. 2989, 2018.

[6] H. Ullah, M. Hussain, N. Abbas, H. Ahmad, M. Amer, and M. Noman, "Numerical investigation of modal and fatigue performance of a horizontal axis tidal current turbine using fluid-structure interaction," Journal of Ocean Engineering and Science, vol. 4, no. 4, pp. 328-337, 2019.

[7] P. Qian, B. Feng, H. Liu, X. Tian, Y. Si, and D. Zhang, "Review on configuration and control methods of tidal current turbines," Renewable and Sustainable Energy Reviews, vol. 108, pp. 125-139, 2019.

[8] Y. Li, H. Liu, Y. Lin, W. Li, and Y. Gu, "Design and test of a $600-\mathrm{kW}$ horizontal-axis tidal current turbine," Energy, vol. 182, pp. 177-186, 2019.

[9] P. Li, W. Hu, R. Hu, and Z. Chen, "The primary frequency control method of tidal turbine based on pitch control," Energy Procedia, vol. 145, pp. 199-204, 2018.

[10] Y.-J. Gu, Y.-G. Lin, Q.-K. Xu, H.-W. Liu, and W. Li, "Bladepitch system for tidal current turbines with reduced variation pitch control strategy based on tidal current velocity preview," Renewable Energy, vol. 115, pp. 149-158, 2018.

[11] C. H. Frost, P. S. Evans, M. J. Harrold, A. Mason-Jones, T. O’Doherty, and D. M. O’Doherty, “The impact of axial flow misalignment on a tidal turbine," Renewable Energy, vol. 113, pp. 1333-1344, 2017.

[12] S. Sangiuliano and S. Mastrantonis, "From Scotland to new Scotland: constructing a sectoral marine plan for tidal energy for nova scotia," Marine Policy, vol. 84, pp. 1-11, 2017.

[13] S. M. Alfakih, T. De, S. Jawad Ali Shah, and K. Hayat, "Simulation model of single structured tower hybrid wind and tidal energy cultivation based on Yemen's south west coast," E3S Web of Conferences, vol. 107, pp. 4-7, 2019.

[14] L. C. Eme, J. A. Ulasi, A. I. Alade Tunde, and A. C. Odunze, "Hydrokinetic turbines for power generation in Nigerian river basins," Water Practice and Technology, vol. 14, no. 1, pp. 71-80, 2019.

[15] Z. J. Wang and Z. W. Wang, "A review on tidal power utilization and operation optimization," IOP Conference Series: Earth and Environmental Science, vol. 240, no. 5, Article ID 052015, 2019.

[16] J. I. Encarnacion, C. Johnstone, and S. Ordonez-Sanchez, "Design of a horizontal Axis tidal turbine for less energetic current velocity profiles," Journal of Marine Science and Engineering, vol. 7, no. 7, p. 197, 2019.

[17] S. Draycott, G. Payne, J. Steynor, A. Nambiar, B. Sellar, and V. Venugopal, "An experimental investigation into non-linear wave loading on horizontal axis tidal turbines," Journal of Fluids and Structures, vol. 84, pp. 199-217, 2019.

[18] M. Nachtane, M. Tarfaoui, K. Hilmi, D. Saifaoui, and A. El Moumen, "Assessment of energy production potential from tidal stream currents in Morocco," Energies, vol. 11, no. 5, p. 1065, 2018.

[19] C. Sun, W. H. Lam, S. S. Lam, M. Dai, and G. Hamill, "Temporal evolution of seabed scour induced by darrieus-type tidal current turbine," Water, vol. 11, no. 5, p. 896, 2019.

[20] C. Sun, W. H. Lam, M. Dai, and G. Hamill, "Prediction of seabed scour induced by full-scale darrieus-type tidal current turbine," Journal of Marine Science and Engineering, vol. 7, no. 10, p. 342, 2019.

[21] W. Tian, Z. Mao, and H. Ding, "Design, test and numerical simulation of a low-speed horizontal axis hydrokinetic turbine," International Journal of Naval Architecture and Ocean Engineering, vol. 10, no. 6, pp. 782-793, 2018. 
[22] M. J. Suárez-López, R. Espina-Valdés, V. M. Fernández Pacheco, A. Navarro Manso, E. Blanco-Marigorta, and E. Álvarez-Álvarez, "A review of software tools to study the energetic potential of tidal currents," Energies, vol. 12, no. 9, p. 1673, 2019.

[23] Y. Haditiar, M. R. Putri, N. Ismail, Z. A. Muchlisin, M. Ikhwan, and S. Rizal, "Numerical study of tides in the Malacca Strait with a 3-D model," Heliyon, vol. 6, no. 9, Article ID e04828, 2020.

[24] M. Ikhwan, Y. Haditiar, R. Wafdan et al., "Wind driven circulation in Makassar Strait during monsoon 2017," IOP Conference Series: Earth and Environmental Science, vol. 348, Article ID 012062, 2019.

[25] S. Rizal, "General circulation in the malacca strait and andaman sea: a numerical model study," American Journal of Environmental Sciences, vol. 8, no. 5, pp. 479-488, 2012.

[26] M. Ramli, "Amplitude amplification factor of Bi-chromatic waves propagation in hydrodynamic laboratories," IAENG International Journal of Applied Mathematics, vol. 46, no. 1, pp. 29-34, 2016.

[27] M. Ramli, "On the maximal temporal amplitude of down stream running nonlinear water waves," Tamkang Journal of Mathematics, vol. 41, no. 1, pp. 51-69, 2010.

[28] M. Ramli, S. Munzir, T. Khairuman, and V. Halfiani, "Amplitude increasing formula of bichromatic wave propagation based on fifth order side band solution of Korteweg de Vries equation," Far East Journal of Mathematical Sciences, vol. 93, no. 1, pp. 97-117, 2014.

[29] D. Fadhiliani, V. Halfiani, M. Ikhwan et al., "The dynamics of surface wave propagation based on the benjamin bona mahony equation," Heliyon, vol. 6, no. 5, Article ID e04004, 2020.

[30] S. Rizal, R. Wafdan, Y. Haditiar, M. Ramli, and V. Halfiani, "Numerical study of lee waves characteristics in the ocean," Journal of Engineering Science and Technology, vol. 15, no. 2, pp. 1056-1078, 2020.

[31] S. Benelghali, M. E. H. Benbouzid, J. F. Charpentier, T. Ahmed-Ali, and I. Munteanu, "Experimental validation of a marine current turbine simulator: application to a permanent magnet synchronous generator-based system secondorder sliding mode control," IEEE Transactions on Industrial Electronics, vol. 58, no. 1, pp. 118-126, 2011.

[32] S. L. Ward, P. E. Robins, M. J. Lewis, G. Iglesias, M. R. Hashemi, and S. P. Neill, "Tidal stream resource characterisation in progressive versus standing wave systems," Applied Energy, vol. 220, pp. 274-285, 2018.

[33] R. Martinez, G. S. Payne, and T. Bruce, "The effects of oblique waves and currents on the loadings and performance of tidal turbines," Ocean Engineering, vol. 164, pp. 55-64, 2018.

[34] X. Yin, M. Lei, and H. Pan, "Direct optimal power extraction control for a tidal turbine system based on fuzzy power tuning," Ocean Engineering, vol. 170, pp. 426-433, 2018.

[35] B. Whitby and C. E. Ugalde-Loo, "Performance of pitch and stall regulated tidal stream turbines," IEEE Transactions on Sustainable Energy, vol. 5, no. 1, pp. 64-72, 2014.

[36] J. C. Dai, Y. P. Hu, D. S. Liu, and J. Wei, "Modelling and analysis of direct-driven permanent magnet synchronous generator wind turbine based on wind-rotor neural network model," Proceedings of the Institution of Mechanical Engineers, Part A: Journal of Power and Energy, vol. 226, no. 1, pp. 62-72, 2012.

[37] M. Elzalabani, F. H. Fahmy, A. E.-S. A. Nafeh, and G. Allam, "Modelling and simulation of tidal current turbine with permanent magnet synchronous generator," TELKOMNIKA
Indonesian Journal of Electrical Engineering, vol. 13, no. 1, pp. 57-64, 2015. 